$5 B 931$
.93
$C .2$

THE ANIUAL LOSS OCCASIONED BY DESTRLCTIVE INSECTS IN THE UNITED STATES.

BY

C. L. MARLATT,

Assistant Entomologist, in Charge of Experimental Field Work, Bureau of Entomology.

[Repitnt from Yearbook of Departuent of Agrictlture for 1904.]

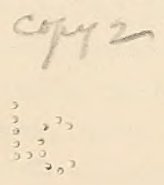




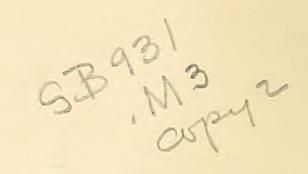

\section{CONTENTS.}

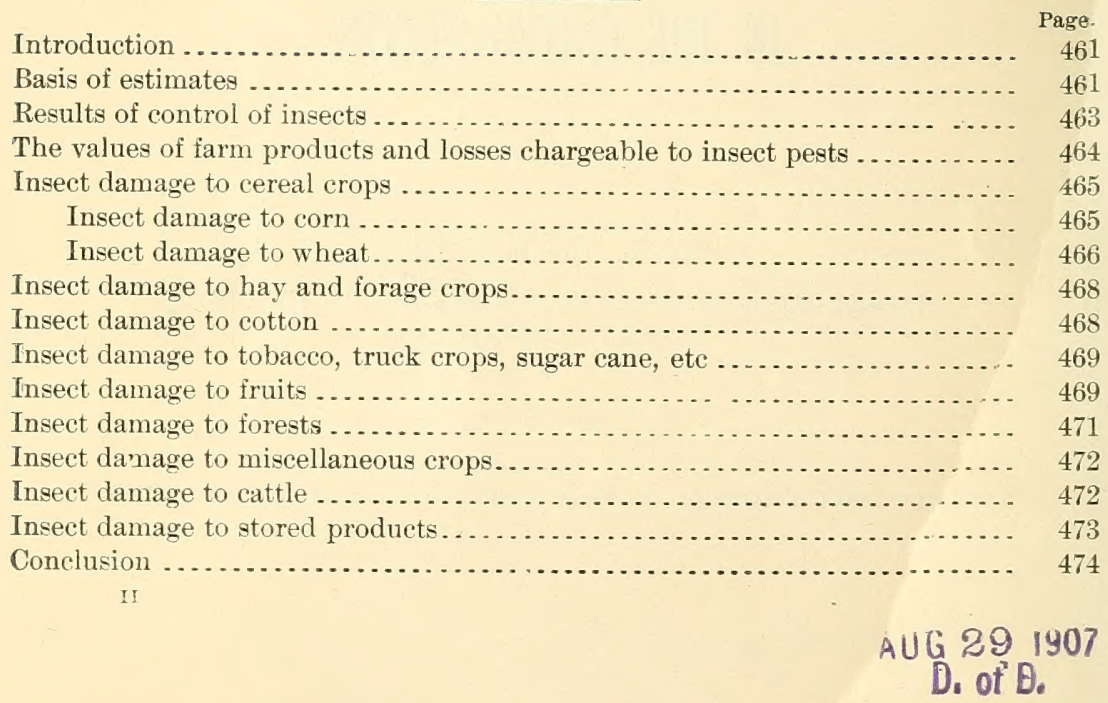




\title{
THE ANNUAL LOSS OCCASIONED BY DESTRUCTIVE INSECTS IN THE UNITED STATES.
}

\author{
By C. L. Marlatt,
}

Assistant Entomologist, in Charge of Experimental Field Work, Bureau of Entomology.

\section{INTRODUCTION.}

In no country in the world do insects impose a heavier tax on farm products than in the United States. The losses resulting from the depredations of insects on all the plant products of the soil, both in their growing and in their stored state, together with those on live stock, exceed the entire expenditures of the National Government, including the pension roll and the maintenance of the Army and the Navy. Enormous as is the total value of all farm products in this country, it would be very much greater were it not for the work of these injurious insects. The statistics of agricultural products for the year 1889, of the Twelfth Census, and for subsequent years, gathered by the Bureau of Statistics of this Department, indicate an annual value of all the products of the farm of about $\$ 5,000,000,000$. To one familiar with the work of the important insect pests of the different agricultural products entering into this total it is comparatively easy to approximate the probable shrinkage due to insects. The detailed consideration of such shrinkages which follows indicates that they will rarely fall below 10 per cent, and in years of excessive insect damage may amount to 50 per cent or even more of the important staple products of the farm. An annual shrinkage of 10 per cent is a low estimate, which is more often exceeded than fallen below, and indicates, at current farm prices, a money loss of $\$ 500,000,000$ - the minimum yearly tax which insects lay on the products of the farm. This total comprises, however, only losses suffered by the growing and maturing crops and annually by live stock, and does not include two very considerable and legitimate items, namely, the loss occasioned by insect pests to farm products, chiefly cereals and forage crops, in storage, and to natural forests and forest products. As shown in the consideration of these two sources of loss presented below, at least $\$ 100,000,000$ must be assigned to each, making a total annual tax chargeable to insects of $\$ 700,000,000$.

\section{BASIS OF ESTIMATES.}

Throughout this paper the estimate of losses in dollars is based on the farm price of the crop actually harvested, and does not, therefore, take into account the possible reduction in value which would follow the marketing of the larger crop. While it is true that prices are 
regulated by production, the factor of distribution may often predominate, so that large crops in certain countries may sometimes hring good prices and small crops low prices. During the last ten years, for example, the price of wheat in this country has exhibited little if any relation to our own production. The bumper wheat crop of 1901 of nearly $750,000,000$ bushels brought to the farmer 23 cents a bushel more than the crop of 1894 , which was $300,000,000$ bushels less, or but little more than half the production of 1901; and this year (1904) the farmer is getting nearly $\$ 1$ a bushel for his wheat on a crop iarger than the average.

Some definite means of estimating losses must be assumed, and any effort to scale down these losses by reckoning possible enhancement of the market price in view of the conditions just cited would come more in the category of pure guesswork and be open to quite as great objection as the plan adopted. As an offset to possibly enhanced values due to shrinkages occasioned by insects, moreover, are certain very legitimate items of cost. A very considerable item of loss properly chargeable to insects is the annual expenditure devoted to their control, which, except in the case of certain fruit and truck crops, has not been considered in the estimates. This amounts to a very considerable percentage of the value of the crop in the case of orchard fruits, truck crops, and such field crops as cotton and tobacco. In the case of the cereals, protection is chiefly secured by farm practices, such as rotation of crops, variations in the time of planting, etc., and this also applies, to some extent, to cotton, tobacro, and truck crops. In estimating the losses due to the codling moth, for illustration, it is shown that over $\$ 8,000,000$ a year is expended in spraying apple trees, allowing a cost of only 5 cents per tree. In the case of citrus fruits the cost of gassing and spraying ranges from 5 cents to $\$ 1.50$ per tree.

Another legitimate class of losses not included in the estimate is the secondary losses which necessarily result from diminished products. For example, the excessive reduction in winter wheat through the Hessian fly ravages in 1900 put a serious check upon milling operations throughout the region worst affected and caused very heavy loss in this field of industry. Similarly a shortage of cotton may so increase the values as to lead to the shutting down of cotton mills, as has been illustrated recently. A shortage of grains means a corresponding loss to the railroads and other transportation companies and to shippers. In other words, any material shrinkage in an important product starts a train of losses to the end of the chapter, the total amount of which is quite beyond calculation or estimate.

The writer believes that these omitted items of loss will make good any difference of price which might result from the larger crops if insect damage were entirely eliminated. Outside of the cash value of 
the crop, furthermore, is the actual material loss in produets, which is absolute so far as the consumer is concerned. The importance of this loss will vary with the nature of the crop. With perishable products, such as fresh fruits and regetables, the losses due to insects may be of minor importance. For example, if the apple crop were increased by 25 or 50 per cent of marketable fruit, values would probably shrink a corresponding amount, and the demands of consumption and the possibilities of storage be very greatly exceeded, so that there would actually be very little benefit, if any, to the producer. On the other hand, in the case of staple products of long keeping quality, as grains, cotton, sugar, lumber products, etc., the loss may be reckoned as more nearly complete, and the chief loss due to insects falls in this latter class.

\section{RESULTS OF CONTROL OF INSECTS.}

Enormous as is the annual loss which may now be fairly charged tc, insects, it would undoubtedly be vastly greater if such pests were left absolutely unchecked and no efforts were made to limit their operations. Were it not for the methods of controlling insect pests, resulting from the studies of the Bureau of Entomology and of the official entomologists of the various States, and the practice of these measures by progressive farmers and fruit-growers, the losses from insects would be greatly increased. Familiar illustrations of savings from insect losses will occur to anyone familiar with the work in economic or applied entomology in this country. The cotton worm, before it was studied and the method of controlling it by the use of arsenicals was made common knowledge, levied in bad years a tax of $\$ 30,000,000$ on the cotton crop. The prevention of loss from the Hessian fly, due to the knowledge of proper seasons for planting wheat, and other direct and cultural methods, results in the saring of wheat to the farm value of from $\$ 100,000,000$ to $\$ 200,000,000$ annually. Careful statistics show that the damage from the codling moth to the apple is limited two-thirds by the adoption of the arsenical sprays, banding, and other methods of control, representing a saving of from $\$ 15,000,000$ to $\$ 20,000,000$ in the value of this fruit product alone. The existence and progress of the citrus industry of California were made possible by the introduction from Australia of a natural enemy of the white scale, an insect pest which was rapidly destroying the orange and lemon orchards, this introduction representing a saving to the people of that State of many million dollars every year. The rotation of corn with oats or other crops saves the corn crop from the attacks of the root worm to the extent of perhaps $\$ 100,000,000$ annually in the chief corn-producing regions of the Mississippi Valley. The cultural system of controlling the boll weevil is already saving the farmers of Texas many millions of dollars, and, in fact, making the continuance of cotton growing possible; and scores of similar illustrations could be cited. 
The losses occasioned by insects to farm products exhibit a wide range in different years, due, as a rule, to favorable or unfavorable climatic conditions, and also to the abundance, from time to time, of natural enemies. The result is more or less periodicity in the occurrence of bad insect years. In other words, periods of unusual abundance of particular insect pests are, as a rule, followed by a number of years of comparative scarcity. Furthermore, seasons which may be favorable to one insect may prove unfavorable to others, hence there may be not only periodicity in the occurrence of the same insect, but more or less of a rotation of the different insect pests of particular crops.

THE VALUES OF FARM PRODUCTS AND LOSSES CHARGEABLE TO INSECT PESTS.

In the table following, the value of certain farm products, namely, the cereals, hay, cotton, and tobacco, is based on the reports of the Bureau of Statistics of this Department for 1904. The other values are taken from the census figures of 1900 . The values assigned to farm products are given in round numbers for convenience in citation, and allied products are thrown together to get a more compact and readily understood statement. The last two columns, indicating the shrinkage due to insect work, are based on the crop actually harvestedthat is to say, except for such damage the crop would have been 10 or 20 per cent greater. It will be noted also that the total value of farm products is greater than that given in the opening paragraphs of this article. This is accounted for by the fact that for the purposes of this table, indicating insect damage, no subtractions are necessary to represent the farm products consumed by live stock, inasmuch as the damage due to insects is to the growing and maturing crop, and the losses indicated for the crops and for animal products are independent.

Annual values of farm products and losses chargeable to insect pests.

\begin{tabular}{|c|c|c|c|}
\hline Produet. & Value. & $\begin{array}{l}\text { Percent- } \\
\text { age of } \\
\text { loss. }\end{array}$ & Amount of loss. \\
\hline Cereals. & $\$ 2,000,000,000$ & 10 & $\$ 200,000,000$ \\
\hline Hay ...... & $530,000,000$ & 10 & $53,000,000$ \\
\hline Cotton........ & $600,000,000$ & 10 & $60,000,000$ \\
\hline Tobacco...... & $53,000,000$ & 10 & $5,300,000$ \\
\hline Truek crops.. & $265,000,000$ & 20 & $53,000,000$ \\
\hline Sugars. & $50,000,000$ & 10 & $5,000,000$ \\
\hline Fruits ....... & $135,000,000$ & 20 & $27,000,000$ \\
\hline Farm forests... & $110,000,000$ & 10 & $11,000,000$ \\
\hline Miscellaneous crops.... & $58,000,000$ & 10 & $5,800,000$ \\
\hline Animal produets $. . . \ldots \ldots \ldots . . . .$. & $1,750,000,000$ & 10 & $175,000,000$ \\
\hline \multirow{4}{*}{ 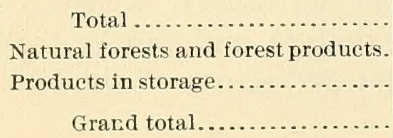 } & $5,551,000,000$ & & $595,100,000$ \\
\hline & & & $100,000,000$ \\
\hline & & & $100,000,000$ \\
\hline & & & $795,100,000$ \\
\hline
\end{tabular}




\section{INSECT DAMAGE TO CEREAL CROPS.}

Only the losses to the two more important cereals, corn and wheat, will be discussed in this paper, as the injury to oats, barley, rye, etc., will average about the same percentage and need not be specifically analyzed.

INSECT DAMAGE TO CORN.

In point of quantity and value corn is the leading cereal crop of the United States. Its annual farm value in later years has nearly equaled and sometimes exceeded $\$ 1,000,000,000$. While less subject to insect damage than wheat, the next most important cereal, the corn product would be considerably greater were it not for important insect pests. The work of several of these is obscure, and many farmers are entirely ignorant of the existence even of some of the worst enemies of this crop. In this last category falls the work of the corn root worm (Diabrotica longicornis), which ordinarily passes unnoticed, or at least is often misunderstood. The larva of this insect feeds on the roots of young corn, and in regions of bad attack may cause an almost entire loss of the stand. The corn root worm, together with one or two allied species working in substantially the same way, causes an annual loss of at least 2 per cent of the crop, or some $\$ 20,000,000$.

Perhaps the next most important insect pest of this cereal is the boll worm or ear worm. This insect, as shown by Mr. A. L. Quaintance, special field agent of this Bureau, probably attacks from 90 to 100 per cent of the ears of sweet corn throughout the country, and in the South practically an equal percentage of the ears of field corn, as shown by actual counts in the field made during the years 1902 and 1903. The average loss in the number of kernels to an attacked ear is 15 per cent, or, if allowance be made for the smaller size of the terminal kernels, at least a loss of $7 \frac{1}{2}$ per cent. The percentage of loss is less in the great corn areas of the Northern and Middle States, but a 2 per cent loss for the United States chargeable to this insect is certainly well within the limits of actual damage, and would, for the corn crop of 1904 , indicate a loss of over $\$ 20,000,000$.

Of perhaps equal importance to this crop are the depredations of the chinch bug. Chinch bug injury is, as a rule, more marked where corn is grown in the neighborhood of wheat or other small grains, and in such cases the migration of the chinch bug from wheat to corn may often result in the total destruction of considerable areas of corn. The chinch bug is a strong flier also, and at the period of migration in midsummer corn is often attacked, the loss in the case of this cereal being, however, very much less than in the case of wheat. For the country as a whole, however, the loss from the chinch bug, taking one 
year with another, will probably be 2 per cent of the crop, or, estimating from the crop of $1904, \$ 20,000,000$.

Every year in different sections of the country there is notable injury to corn by such insects as bill-bugs, the various wireworms, cutworms, and army worms, stalk-borers, various species of locusts or grasshoppers, corn plant-lice, and other insects, to a total of fifty fairly important species. These minor pests undoubtedly cause a loss of an additional 2 per cent, making a total annual injury of 8 per cent, and indicating a loss of $\$ 80,000,000$.

INSECT DAMAGE TO WHEAT.

Of the cereal crops of this country wheat suffers most from insect depredations. Of the large number of insects which depredate on this cereal, the three important species are the Hessian $\mathrm{fly}$, the chinch bug, and the grain plant-louse, using the latter term to include several allied species which work in much the same manner. The chinch bug is notably a wheat pest, although its damage to other cereals and forage crops is very considerable. The losses from the depredations of this insect on wheat in single States have ranged between $\$ 10,000,000$ and $\$ 20,000,000$ in one year. A very reasonable average annual estimate of loss, taking the country as a whole, would be 5 per cent of the value of the wheat crop, which would indicate about $\$ 20,000,000$ a year chargeable to this insect.

The Hessian fly is distinetly a wheat pest, although doing some damage also to rye and barley. The losses due to this insect will be considered more in detail to indicate their nature specifically and to illustrate the exactness and reliability which may sometimes characterize records of this kind relating to particular pests of a single crop.

The season of 1900 is notable in Hessian-fly annals as exhibiting the most destructive work of this pest in recent years. The fly was very generally present throughout the main wheat-growing districts of the Ohio and Mississippi valleys, but its ravages were this year concentrated particularly in Ohio and Indiana. The statistics of the acreage and yield of wheat and value of the crop for this year for the States mentioned reflect very plainly the loss occasioned by this pest. The wheat area in these two States in 1900 and the years immediately preceding was about 5,000,000 acres. Chiefly on account of the ravages of the Hessian fly more than half of this acreage $(2,577,000$ acres) had been abandoned and planted to other crops prior to May 1, 1900, as shown by the records collected by the Bureau of Statistics of this Department. The abandonment was about 40 per cent for Ohio and 60 per cent for Indiana. The cost of the preparation of soil, planting, and seed wheat for this abandoned acreage is all that need be reckoned, inasmuch as it was possible to use the land for other crops, such as corn or oats. The loss in labor and material indicated will approximate 
$\$ 3.50$ per acre, giving a total of over $\$ 9,000,000$. Of the remaining wheat acreage, the average yield per acre for this year in Ohio was 6 bushels as against 15.3 bushels for the year following, 14.2 bushels for the year previous, and nearly 17 bushels for the years 1897 and 1898. For Indiana, the yield per acre in 1900 was only 5.3 bushels as contrasted with 15.8 bushels for 1901, and 15.6 and 9.8 bushels, respectively, for 1898 and 1899. In other words, a decrease in the yield per acre is shown of nearly two-thirds, for these two States, for the area in wheat which was left for harvesting. The Hessian fly does more or less damage every year, which reduces the average yield per acre, and, therefore, if such damage be eliminated, the average yield per acre should be in the neighborhood of 15 bushels, indicating a loss for this year from the Hessian fly of nearly 10 bushels per acre for the area harvested, or, for the two States, of $24,230,000$ bushels of wheat, of approximately a farm value (at the low price for that year) of $\$ 15,000,000$. This loss, combined with the $\$ 9,000,000$ indicated for the abandoned acreage, gives a total direct loss for these two States of over $\$ 24,000,000$. These figures, enormous as they are, are based on the careful statistical records of the acreage, yield, and prices of 1900 collected by the Statistician of the Department, working entirely independently of the Bureau of Entomology.

During this year the damage in other wheat-producing States was notable. For example, more than 20 per cent of the planted area of Michigan was abandoned, and lesser amounts in other States, with great shrinkages in the yield of acreage which was actually harvested. The loss, therefore, for this single season, due to the Hessian fly, undoubtedly approached $\$ 100,000,000$.

The losses occasioned by this insect, while showing great fluctuation, as indicated above, are an annual tax on the wheat crop. Except in cases of exceptional severity they pass, however, comparatively unnoticed. For example, the Hessian fly is not being especially complained of this year (1904), yet the agent investigating the insect enemies of cereal crops in the Ohio valley reports that many fieldsi show injury to the extent of from 50 to 75 per cent. In comparatively few years does this insect cause a loss less than 10 per cent of the crop, or the equivalent of a shrinkage of over $50,000,000$ bushels in the yield, or, on the valuation of the crop for 1904, of over $\$ 40,000,000$.

The losses due to wheat plant-lice are often very considerable, resulting in a heavy shrinkage of wheat at the moment of maturity, when the wheat heads may be corered with these lice, sucking away at the soft, forming kernels. The yield of badly infested fields may be reduced at this time from 25 to 50 per cent, and when weather conditions are favorable this pest is often abundant over enormous areas. 
The annual loss oceasioned by wheat plant-lice probably does not fall short of 2 or 3 per cent of the crop.

The many other insects depredating on wheat, including grasshoppers, the wheat midge, several species of sawflies, and the cutworms and army worms, will swell the total of loss to at least 20 per cent of the crop. In other words, were it not for the attack of these pests the wheat crop would be one-fifth greater than it now is, or have an additional value of approximately $\$ 100,000,000$.

The insect damage to other cereal crops probably falls short of 10 per cent. A 10 per cent average, however, for all the cereals, is certainly a reasonable one and is the basis of the loss indicated in the general table.

\section{INSECT DAMAGE TO HAY AND FORAGE CROPS.}

The damage by destructive insects to hay and forage crops is more obscure and less generally understood than in the case of any other farm products. Certain of the larger insects depredating on hay and forage crops are commonly known. These include the various species of locusts or grasshoppers, army worms, and cutworms. Very little understood and generally overlooked, however, are the webworms and small grass worms (Crambus spp.) which work about the base or roots of the plants, and which are so abundant that at the proper season the moths flit up in front of one at every step. Swarming also in grass lands are many species of minute leaf-hoppers which reduce the yield enormously, their small size being more than offset by their prevalence and numbers. Obscure, but very important also, are the white grubs, which work on the roots and often kill the grass outright over large areas, and everywhere tax production considerably. In the same class in habit are the meadow worms or leather jackets, the grassroot feeding larvæ of the crane flies. A 10 per cent shrinkage from these and other pests in grasses and forage plants is a minimum estimate.

\section{INSECT DAMAGE TO COTTON.}

The principal insect depredators on cotton are the cotton boll weevil, the bollworm, and the leaf worm. Many other insects, however, inflict minor damage. The loss chargeable to the boll weevil, from the very conservative estimate of $\mathrm{Mr}$. W. D. Hunter, the agent charged with the study of this insect in Texas, represents, for the year 1904, some $\$ 20,000,000$.

The bollworm is chiefly destructive in the southwestern cottonproducing States of Mississippi, Indian Territory, Oklahoma, Arkansas, Louisiana, and Texas, and causes a damage in these States of from 2 to 60 per cent of the crop. East of these States comparatively little damage is done by this insect. The damage for the States first 
mentioned, where this insect is most injurious, has been very conservatirely estimated by $\mathrm{Mr}$. A. L. Quaintance at \pm per cent of the crop of these States, and indicates an annual loss of some $\$ 12,000,000$.

The cotton leaf worm in year's of excessive damage, before the use of arsenical poisoning was a common practice, caused a loss of $\$ 20,000,000$ to $\$ 30,000,000$. The present damage resulting from this pest is very much reduced, but with the increased acreage of cotton an annual loss of from $\$ 5,000,000$ to $\$ 10,000,000$ may be conservatively estimated. Without counting the losses due to many minor insect depredators, we have already a total loss of more than $\$ 40,000,000$ chargeable to three important insect pests of this staple.

INSECT DAMAGE TO TOBACCO, TRUCK CROPS, SUGAR CANE, ETC.

Detailed statements relative to the insect losses to the crops enumerated above will not be attempted in the space at command. All of these crops are subject to the attacks of important insect pests, and a reasonable estimate of the annual damage is 10 per cent of the value of the first and last named crops, and fully 20 per cent in the case of truck crops. Vegetables and other truck crops are especially subject to insect injury, and, furthermore, in the case of these crops there is always a large expenditure in the control of insects, the items of actual damage and cost of control together probably making the tax due to insects double the normal 10 per cent rate.

\section{INSECT DAMAGE TO FRUITS.}

The orchard and small fruits suffer heavily from insect pests, both directly and because of the expensire methods of treatment necessary to prevent still greater losses. The examination of this subject will be limited to the insect injuries to the apple. There are several hundred insects which depredate on the roots, trunk, foliage, and fruit of the apple. The important pests are the woolly aphis, injuring the roots; the trunk and limb borers; the leaf worms, canker worms, and tent caterpillars; and the various scale insect pests, including the San Jose scale. Injuring the fruit are the codling moth, the curculio, and the apple maggot. It is a very difficult matter to estimate the amount of loss chargeable to these various insects. Those affecting the health and vigor of the tree itself lessen the productiveness at least 17 per cent, estimating 5 per cent for the woolly aphis, 2 per cent for borer's, and 10 per cent for the plant-lice, scale insects, and caterpillars and other leaf depredators.

Very notable injury to the fruit also results from the work of the curculio and the apple maggot, but space will be taken merely to discuss somewhat in detail the injury chargeable to the codling moth. This species probably causes a greater monetary loss than any of the other enemies to fruits. Various estimates of the loss due to its attacks 
have been made, and in general it is believed that roughly it causes a loss of from one-fourth to one-half of the apple crop of the United States every year. Mr. C. B. Simpson, while special field agent of this Bureau, gave some of the recent estimates of losses in rarious States:

In 1889 Professor Forbes reached the conclusion that the annual loss in the State of Illinois was $\$ 2,375,000$. It is estimated that in 1892 the insect caused $\$ 2,000,000$ loss to Nebraska apple growers. Professor Slingerland estimates that in 1897 the insect taxed the apple growers of New York $\$ 2,500,000$. In 1900 one-half of the crop of Idaho was damaged, while in 1901 the loss was much greater. Mr. McPherson estimates that in Idaho the loss in 1902 was $\$ 250,000 . * *$ * In many sections of the Pacific Northwest the loss was from 50 to 75 per cent.

An estimate made by Mr. Simpson and the writer" is perhaps as nearly accurate as may be in indicating the quantity lost in barrels of merchantable apples. The best available estimates of the apple crop of the United States are those compiled by the American Agriculturist, and from these it is found that the arerage crop for the five years from 1898 to 1902 was $47,000,000$ barrels. This includes only apples of first and second quality.

It has been shown by careful observations in various apple-growing States that the codling moth, as already indicated, may cause a loss of from 20 to 40 per cent of fruit which would otherwise be sound and merchantable. For reasons to be given later on, in computing the actual monetary loss to the apple growers of this country by the codling moth, we prefer to take the lower of these two estimates. This 20 per cent decrease in merchantable apples would represent some $12.000,000$ barrels, and at an average profit of $\$ 1$ per barrel indicates a loss of $\$ 12,000,000$, less the value of this fruit for cider purposes, supposing that it is all so used. The average price for cider apples will not exceed 30 cents per barrel, which would represent a reduction of $\$ 3,600,000$, learing a net loss of $\$ 8,400,000$. The loss throughout the country in small orchards supplying local needs undoubtedly averages much higher than in the large commercial orchards, which supply the bulk of the fruit to the markets. The estimate made by Mr. Simpson of the loss in such home orchards is $\$ 3,000,000$, which, added to our former figures, gives a total direct loss to the apple crop annually from the codling moth of $\$ 11,400,000$.

One would be perfectly justified in estimating the actual loss in merchantable apples at a much higher figure than 25 per cent, and an average might be assigned of 35 or 40 per cent at least, which would have rery greatly increased the apparent monetary loss. There are, however, considerations which offset the monetary loss occasioned by the codling moth and undoubtedly reduce it very considerably. The apple is a perishable fruit and must be consumed within a limited 
period. It is not like wheat and other cereals, the standard grades of which have fairly fixed values and which may be kept indefinitely. The cold-storage system has very much extended the marketing period of apples, but this affects only a limited amount, measured by the actual cold-storage capacity, and the bulk of the crop must find an immediate market. Therefore, if the additional fruit which is now rendered unsalable by the codling moth should be thrown on the market, the actual price of apples would probably be affected even more than the increased supply would indicate. The increase in our export apple trade, which is being actively encouraged by the Department of Agriculture, and the development of cold-storage facilities for fruit will undoubtedly increase the market for apples from year to year. Nevertheless, one is warranted in taking the lower estimates considered above, in view of the probable decrease in prices which would result if the codling moth damage did not materially reduce the crop every year.

An additional and important item of loss is the annual charge for spraying or otherwise treating apple trees, without which, as indicated above, the losses from the codling moth and curculio would be doubled if not trebled. Practically all commercial apple orchards are sprayed annually with arsenicals, and banding of trees and other means of protection are also practiced. Of the $200,000,000$ apple trees enumerated in the last census, on the authority of Mr. Taylor, at least 165,000,000 are in bearing condition, and the cost of spraying and other treatments for these will range between 5 and 10 cents per tree. As an offset to untreated orchards, the lower estimate of cost may be taken, namely, 5 cents per tree, which gives a charge for treatment of $\$ 8,250,000$. Combining the direct shrinkage or loss and the cost of protection from still greater loss gives a total tax chargeable to the codling moth of nearly $\$ 20,000,000$.

The insect losses to other deciduous fruits are quite as heavy as in the case of the apple, and especially when the treatments for the San Jose scale and other scale pests are considered; and in the case of citrus fruits the cost of treatment is much greater and the actual losses again heavy. We are warranted, therefore, in placing the loss to fruits from insect pests as high as 20 per cent annually.

\section{INSECT DAMAGE TO FORESTS.}

The valuation of farm forests, namely, planted forests of artificially wooded areas on farms, is given in the last census at $\$ 110,000,000$. A brief consideration of the numerous insect pests of such plantings, including the borers-which often almost utterly destroy the trees, as in the case of the black locust - the leaf defoliators, and many other varieties of depredating insects, indicates that a 10 per cent annual loss of such plantings is not an unreasonable estimate. 
Of very much greater significance and economic importance, however, is the insect loss to natural forests and to wood, lumber, and manufactures. The annual losses occasioned by insect pests to such forests and forest products have been estimated by Dr. A. D. Hopkins, special agent in charge of forest insect investigations, at not less than $\$ 100,000,000$. This is based on late stumpage values and on the wholesale prices of the commercial products; in other words, it covers both the losses from insect damage to standing timber and to the crude and manufactured forest products. The annual loss to growing timber is conservatively placed at $\$ 70,000,000$. This represents a loss of $\$ 20,000,000$ annually to hardwood timber, as indicated by Doctor Hopkins in his article in the Yearbook of this Department for 1903, and $\$ 50,000,000$ annual loss to coniferous forests. As a single illustration of the loss in the last category may be mentioned the destruction in the year 1902 of $600,000,000$ feet of valuable timber in the Black Hills district, representing a cash loss of upward of $\$ 25,000,000$ in one limited area. The damage by insects working in lumber and manufactures of wood is very considerable, and has recently been estimated by Doctor Hopkins to represent a minimum annual loss of 5 per cent of the valuation of such products, amounting to some $\$ 30,000,000$ and completing the total of $\$ 100,000,000$ already indicated. This loss is in addition to the loss to farm forests referred to.

\section{INSECT DAMAGE TO MISCELLANEOUS CROPS.}

A great many minor crops enumerated in the census of 1900 can not be discussed separately, and the valuation of these crops is lumped together and a 10 per cent loss chargeable to insects estimated on the whole, which seems reasonable in view of the examinations already made of the more important farm products.

INSECT DAMAGE TO CATTLE.

The losses due to biting and parasitic insects of cattle are considerable. The principal culprits are the ox warble and various biting flies and ticks. The damage chargeable to the ox warble was very carefully investigated several years ago by a western farm paper, and from the averages reported from the chief eattle States of the Mississippi Valley it was shown that 50 per cent of the cattle received in the Union stock yards at (Chicago during the grubby season (from January to June) were infested and more or less injured by the presence of the larvæ of this insect. The depreciation in the value of hides and the lessened quantity and poorer quality of the beef indieated a total loss during the season in question of over $\$ 3,000,000$. This loss applies only to the cattle coming to the Chicago market during the period mentioned, and is merely an indication of the much greater loss to range and farm stock throughout the country from this one pest. The 
loss for Great Britain from the warble has been estimated to vary from $\$ 10,000,000$ to $\$ 35,000,000$ per annum, and the total for the United States certainly can not fall below that for Great Britain.

The shrinkage or check to fattening due to the annoyance from biting flies and other insect pests of cattle represents a very considerable total every year, probably, in view of the greater prevalence of these pests, much more than is chargeable to the ox warble.

Horses, sheep, and other farm animals are subject to the attacks of similar parasites and other insect enemies, and if all these be considered, including, for example, the buffalo gnats, often very destructive in the South, the many gadflies, botflies, the screw-worm fly, and such parasites as the ticks and lice, a heavy percentage of loss must be reckoned. A 10 per cent annual loss has been assigned, certainly a conservative estimate, which represents a shrinkage in stock values due to insect pests of $\$ 175,000,000$.

\section{INSECT DAMAGE TO STORED PRODUCTS.}

The estimates given in the foregoing relating to vegetable products give the shrinkage due to the attacks of insects to the growing and maturing crops. After these crops have run the gauntlet of insect enemies during their entire period of growth-and this applies notably to the cereal and forage crops and to tobacco and certain truck cropsthey are still subject to the inroads of another class of insect depredators while in storage on the farm, or, in greater accumulations, in elevators and mills, or, again, while in transit, especially in the case f long shipments by sea. The cereals are all kept in storage until consumed, which means a considerable period for the bulk of the crop. The various grain weevils and beetles, flour moths, and other insect

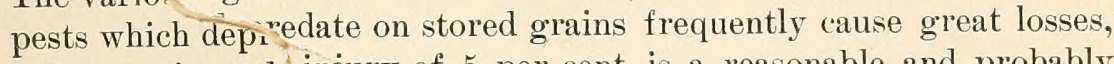
and an estimated injury of 5 per cent is a reasonable and probably minimum figure. Computing this percentage, therefore, on the valuation of the cereal products for 1904, we have indicated an annual loss of $\$ 100,000,000$.

The location of food products for human consumption is in the house storeroom and kitchen, and often this last opportunity for insect damage is improved by various species of the stored-grain pests already referred to. Animal products are attacked by larder beetles, ham beetles, etc., fruits by various fruit and vinegar flies, and the woolens or the household furnishings by carpet beetles, clothes moths, silver fish, etc.

Cured tobacco is especially subject to insect attacks and damage, the most important source of injury being a minute insect known as the cigarette beetle, which not only eats into cigarettes, but all other forms of cured tobacco. It is now widespread in America, oceurring in 
practically all factories, warehouses, and retail establishments, and is frequently the cause of very heavy losses.

In the general table a total loss of $\$ 100,000,000$ is indicated for insects attacking stored products. This is covered by the loss indicated for cereal products alone, and if the other items of loss just enumerated were included a considerable increase in the estimate could legitimately be made.

\section{CONCLUSION.}

A general analysis of the insect losses for this country has been given in the introductory paragraphs. In concluding it is only necessary to emphasize again the fact that these losses, enormous as they are estimated to be, could be legitimately swelled by adding the secondary losses which, in the case of the great staple productions of the farm, follow any considerable shortage and ultimately add to the cost of living for every individual, in addition to creating large commercial disturbances. Furthermore, the cost of protection from insect damage has been considered only in the case of one or two products of the farm. Another considerable insect tax not estimated for is the direct loss and the cost of protection from domestic or household insect pests. Screening of houses against mosquitoes or flies, protection from roaches. clothes moths, and the ravages of the white ant and of various parasitic, insects, are a charge on every household. The white ant in Washing. ton, D. C., alone causes losses of thousands of dollars yearly, and it i/s much more destructive in southern districts. If the smaller or large sums expended for protection from such pests were tabulated for the whole country, the total would probably exceed $\$ 50,000,000$, and mirght be double that amount. An omission perhaps more important than any of these is the indirect loss to the produring and earnins capacity of communities by diseases conveyed by insects. Fsi. example, malaria and yellow fever are dependent solely on certain species of mosquitoes, and typhoid fever is commonly carried, as shown by Dr. Howard, by house flies. The losses from all three of these diseases are enormous, and in the case of yellow fever outbreaks, of en almost beyond computation. With domestic animals the tick, esponsible for Texas fever in the South, has been estimated to cause a annual loss of $\$ 100,000,000$, and other diseases of man and domestic animals will undoubtedly be shown to depend exclusively or largely on biting or other insects. In view of these omissions, the writer is convinced that the total of over $\$ 700,000,000$ annual loss assigned to insect pests in America is below rather than above the ar tual damage. The lessening or preven. tion of this loss is the probler for the economic entomologist to solve. 